\title{
Proteinograma do leite de vacas com mastite subclínica em função do escore de
}

\section{células somáticas}

\author{
Proteinogram of milk from cows with subclinical mastitis as a function of the score of somatic cells \\ Proteinograma de leche de vacas con mastitis subclínica en función del puntaje de células somáticas
}

Recebido: 01/07/2021 | Revisado: 07/07/2021 | Aceito: 08/07/2021 | Publicado: 20/07/2021

Fernanda Antunha de Freitas Alves

ORCID: https://orcid.org/0000-0003-2532-6501 Universidade Federal de Goiás, Brasil E-mail: fernandaantunha@gmail.com Marília Cristina Sola

ORCID: https://orcid.org/0000-0002-2125-4064 Universidade Federal dos Vales do Jequitinhonha e Mucuri, Brasil

E-mail: mcsmarilia@gmail.com

Albenones José de Mesquita

ORCID: https://orcid.org/0000-0002-6273-1015 Universidade Federal de Goiás, Brasil

E-mail: albenones.mesquita@gmail.com

\begin{abstract}
Resumo
Objetivou-se, com o presente estudo, investigar a influência do aumento da CCS na expressão das proteínas do soro de leite por meio da utilização da técnica de separação de proteínas de eletroforese microfluídica em microchip (labon-a-chip). Foram coletadas 104 amostras de leite de vacas em duas propriedades localizadas no Estado de Goiás. As amostras foram analisadas quanto a contagem de células somáticas e eletroforese microfluídica lab-on-a-chip. Para o teste de correlação entre o perfil de proteínas e a CCS foram utilizadas 50 amostras de leite e estas foram estratificadas em cinco grupos de escores de células somáticas, sendo utilizado um delineamento inteiramente ao acaso com cinco tratamentos, avaliado por meio da estatística descritiva e representações gráficas. Verificou-se um aumento significativo no valor do componente proteína em relação aos ECS 1 e 3, 1 e 4 e 1 e 5. Também foi possível observar diferença estatística nos resultados do componente Lactose quando se comparou os ECS 1 e 3 e 3 e 4 . Na avaliação descritiva da variável "Concentração" das proteínas do leite foi possível observar diferenças nos valores das concentrações em função do ECS. Foi possível observar diferença estatística para os resultados obtidos para as proteínas $\alpha$-LA, quando comparados os ECS 1, 2 e 3 e o ECS 5; para a IgG, as amostras de ECS 4 e 5 apresentaram concentrações diferentes das amostras dos ECS 1, 2 e 3; e a proteína LF, apresentou resultados diferentes entre as amostras de ECS 1 e 5. Concluiu-se que proteínas de alta abundância do soro de leite tem sua concentração diminuída em função da severidade da mastite; proteínas de defesa, como Lactoferrina, Lactoperoxidase e IgG e IgM têm aumento em suas concentrações quando se comparam amostras de leite de vacas com mastite subclínica e amostras de leite de vacas sadias; as proteínas Lactoferrina e IgG constituem alvos em potencial para identificar vacas com mastite subclínica a partir de amostras de leite, podendo ser consideradas biomarcadores.
\end{abstract}

Palavras-chave: Contagem de células somáticas; Mastite subclínica; Proteína.

\begin{abstract}
The aim of the present study was to investigate the influence of increased SCC on the expression of milk proteins through the use of analyzes microfluid electrophoresis (lab-on-a-chip). Fifty samples of cow's milk from two properties located in State of Goiás were analyzed. Samples were analyzed for somatic cell counts and lab-on-a-chip microfluidic electrophoresis. For the correlation test between the protein profile and the SCC the samples were stratified into five groups of Scores of Somatic Cell. A completely randomized design with five treatments was used, data were analyzed using descriptive statistics and graphical representations. There was a significant increase in the concentration of the protein component when compaired SSC 1 and 3, 1 to 4 and 1 and 5. It was also possible to observe a statistical difference in the results of the Lactose component when comparing SSC 1 and 3 and 3 and 4 . In the descriptive evaluation of the variable "Concentration" of the milk proteins it was possible to observe differences in the concentration values as a function of SSC. It was possible to observe statistical difference for the results obtained for $\alpha$-LA, when compared to ECS 1,2 and 3 and ECS 5; For IgG, samples from SSC 4 and 5 showed different concentrations of samples from SSC 1,2 and 3; and the LF protein, presented different results between the samples of SSC 1 and 5. We concluded that high abundance whey proteins have their concentration decreased with the occurence
\end{abstract}


of the mastitis; Defense proteins such as Lactoferrin, Lactoperoxidase, IgG and IgM have their concentration increased when comparing milk samples from cows with subclinical mastitis and milk samples from healthy cows; Lactoferrin and $\operatorname{IgG}$ proteins are potential targets for identifying cows with subclinical mastitis in milk samples and may be considered biomarkers.

Keywords: Protein; Somatic cell cout; Subclinical mastitis.

\section{Resumen}

El objetivo de este estudio fue investigar la influencia del aumento de CCS en la expresión de proteínas de suero mediante la técnica de separación de proteínas de electroforesis microfluídica en microchip (lab-on-a-chip). Se recolectaron 104 muestras de leche de vaca en dos granjas ubicadas en el estado de Goiás, las cuales fueron analizadas para conteo de células somáticas y electroforesis microfluídica lab-on-a-chip. Para la prueba de correlación entre el perfil proteico y la CCS, se utilizaron 50 muestras de leche y estas se estratificaron en cinco grupos de puntajes de células somáticas, utilizando un diseño completamente al azar con cinco tratamientos, evaluados mediante estadística descriptiva y representaciones gráficas. Hubo un aumento significativo en el valor del componente proteico en relación a ECS 1 y 3,1 y 4 y 1 y 5 . También fue posible observar una diferencia estadística en los resultados del componente Lactosa al comparar ECS 1 y 3 y 3 y 4 En la evaluación descriptiva de la variable "Concentración" de proteínas de la leche, fue posible observar diferencias en los valores de concentraciones en función de la ECS. Se pudo observar una diferencia estadística para los resultados obtenidos para las proteínas $\alpha$-LA, al comparar ECS 1,2 y 3 y ECS 5; para IgG, las muestras de ECS 4 y 5 tenían concentraciones diferentes que las muestras de ECS 1,2 y 3 ; y la proteína LF mostró resultados diferentes entre las muestras ECS 1 y 5 . Se concluyó que las proteínas de suero de alta abundancia tienen su concentración disminuida debido a la severidad de la mastitis; las proteínas de defensa como la lactoferrina, lactoperoxidasa e $\operatorname{IgG}$ e IgM tienen concentraciones aumentadas cuando se comparan muestras de leche de vacas con mastitis subclínica y muestras de leche de vacas sanas; Las proteínas lactoferrina e IgG son objetivos potenciales para identificar vacas con mastitis subclínica a partir de muestras de leche y pueden considerarse biomarcadores.

Palabras clave: Recuento de células somáticas; Mastitis subclínica; Proteína.

\section{Introdução}

A mastite bovina é considerada a doença de maior ocorrência e importância econômica para a atividade leiteira, acarretando prejuízos decorrentes da diminuição da produção láctea e comprometimento na qualidade do leite (Mao et al., 2015; Sadek et al., 2017).

A contagem de células somáticas (CCS) em amostras de leite cru de vacas tem sido utilizada como padrão ouro para o diagnóstico de mastite subclínica (Harmon, 1994; Rodha \& Pantoja, 2012; Musayeva et al., 2016). No entanto, a CCS nem sempre está correlacionada com infecções do úbere, já que também pode ser afetada por alguns fatores relacionados ao animal, como estágio de lactação, raça, estresse, entre outros (Scheper et al., 1997; Akerstedt et al., 2011).

O leite é um fluido corporal complexo que contém uma grande variedade de proteínas que podem refletir o status sanitário da glândula mamária da vaca e fornecer informações úteis para o diagnóstico de enfermidades (Hogarth et al., 2004; Bislev et al., 2012). Contém seis proteínas maiores ( $\alpha$ s1- caseína, $\alpha$ s- caseína, $\beta$ - caseína, $\kappa$ - caseína, $\alpha$-lactalbumina ( $\alpha$-LA) e $\beta$-lactoglobulina ( $\beta$-LG) e baixos níveis de proteínas derivadas do soro, como albumina (ALB), enzimas, imunoglobulinas e proteínas do complemento, fatores de crescimento e lactoferrina (LF). Proteínas e peptídeos de menor abundância associadas à inflamação podem ser detectados em amostras de leite durante a infecção. Esses componentes possuem funções associadas à defesa do hospedeiro e, alguns, propriedades antimicrobianas (Smolenski et al., 2007; Wheeler et a., 2012; Santos et al., 2018).

Avaliações das mudanças na expressão de proteínas do soro de leite proveniente de vacas com mastite podem aumentar o entendimento dos efeitos da composição na produção de derivados lácteos, na biologia mamária, na função imune da glândula mamária, bem como identificar biomarcadores para detecção precoce desta enfermidade (Reinhardt et al., 2013).

Os testes para identificar indicadores de inflamação podem ser utilizados para rastrear a infecção intramamária e selecionar vacas para análise bacteriológica subsequente. Esses testes podem ser úteis como parâmetros de prognósticos, para indicar a intensidade da inflamação e monitorar a recuperação da vaca (Pyorala et al., 2011). A mudança nos padrões de peptídeos do leite, relacionada a animais com mastite e a animais livres da enfermidade, pode fornecer uma fonte de biomarcadores para a doença. Nesse sentido, o uso de tecnologias avançadas para detecção e análise de peptídeos biomarcadores pode auxiliar no diagnóstico de mastite (Mansor et al., 2013; Santos et al., 2018).

Objetivou-se com o presente estudo, no aspecto geral, investigar a influência do aumento da CCS na expressão das proteínas do 
soro de leite por meio da utilização da técnica de separação de proteínas por eletroforese microfluídica em microchip (lab-on-a-chip). Nos aspectos específicos, avaliar as alterações dos níveis de proteínas em função de diferentes escores de células somáticas em amostras de leite de vacas, contribuir com o conhecimento da composição proteica do leite e das alterações provocadas pela inflamação, além de identificar potenciais biomarcadores para o diagnóstico de mastites subclínicas.

\section{Metodologia}

\section{Estruturação do estudo}

Com o objetivo específico de avaliar a correlação entre escores de células somáticas (ECS) e a expressão de proteínas do soro de leite foram realizadas coletas de amostras de leite cru de vacas em lactação em duas propriedades rurais no Estado de Goiás.

Foram selecionadas duas propriedades, sendo uma localizada no município de Goiânia e outra no município de Goiás. As vacas utilizadas neste estudo eram principalmente das raças Holandesa e vacas mestiças, com média de cinco anos de idade e 19 litros de produção média diária. A coleta das amostras foi realizada em vacas aparentemente sadias e que não apresentavam sinais clínicos de doenças, como a mastite. As duas propriedades possuíam sistema de ordenha mecânica provido de medidor e tanque de refrigeração para armazenamento do leite ordenhado. Para o presente estudo, foram coletadas amostras de leite de 52 vacas que eram ordenhadas três vezes ao dia, sendo a amostragem realizada na segunda ordenha.

\section{Coleta de amostras}

Foram coletadas duas unidades de amostras individuais de todas as vacas em lactação das propriedades que participaram do experimento, sendo uma para análise da CCS e composição centesimal e a outra para análise de eletroforese para identificação das proteínas do soro de leite.

Para o teste de correlação entre o perfil de proteínas e a CCS, as amostras foram estratificadas em cinco grupos, descritos no Quadro 1. Foram analisadas 10 amostras em cada grupo. As que apresentaram resultado de até 100.000 cel/mL foram consideradas provenientes de vacas sadias e consideradas como controle.

Quadro 1. Grupos de divisão das amostras de acordo com a CCS.

\begin{tabular}{|c|c|c|}
\hline $\begin{array}{c}\text { Escore de Células } \\
\text { Somáticas (ECS) }\end{array}$ & Faixa de CCS (x1.000 cels /mL) & $\begin{array}{c}\text { Número de amostras analisadas em } \\
\text { cada grupo }\end{array}$ \\
\hline 1 & $0-100$ & 10 \\
\hline 2 & $101-200$ & 10 \\
\hline 3 & $201-500$ & 10 \\
\hline 4 & $501-1.000$ & 10 \\
\hline 5 & +1.000 & 10 \\
\hline
\end{tabular}

Fonte: Autores (2021).

\section{Amostra individual de leite para análise}

As amostras individuais de leite de cada vaca foram representativas de uma ordenha completa de cada animal, em um período de 24 horas. A coleta do leite em ordenhadeira mecânica de circuito fechado foi realizada com o auxílio de medidores. Após a ordenha completa, o leite foi agitado por meio da permissão de entrada de ar no medidor; a válvula então foi aberta, sendo o volume de $40 \mathrm{~mL}$ de leite vertido nos frascos de coleta. A coleta foi realizada em duplicata, sendo que um dos frascos continha uma pastilha de Bronopol ${ }^{\circledR}$ (D\&F Control Systems, Dublin) para a conservação do leite visando à análise de CCS e de composição centesimal e outra não continha conservante e destinava-se a análise de proteínas.

As amostras foram transportadas ao laboratório, logo após a coleta, em caixas isotérmicas contendo gelo reciclável. 
Os frascos contendo o conservante foram encaminhados ao Laboratório de Qualidade do Leite do Centro de Pesquisa em Alimentos da Escola de Veterinária e Zootecnia da Universidade Federal de Goiás (LQL/CPA/EVZ/UFG) para a realização das análises de CCS e composição centesimal. Já os frascos que não continham conservantes foram encaminhados para o Laboratório de Microbiologia de Alimentos Multiusuário do Centro de Pesquisa em Alimentos da EVZ/UFG.

Antes do armazenamento, as amostras de leite cru sem conservantes foram centrifugadas $2.500 \mathrm{xG}$ e desnatadas. Em seguida foram armazenadas em congeladores à temperatura de $-80^{\circ} \mathrm{C}$ para posterior realização da análise de proteinograma.

\section{Contagem de Células Somáticas e Análise de Composição Centesimal}

A Contagem de Células Somáticas (CCS) foi realizada em equipamento Fossomatic 500 Basic (FOSS ELECTRIC A/S, HILLEROD, DINAMARCA, 2000), cujo princípio analítico baseia-se na citometria de fluxo, sendo o resultado expresso em células/mL (Bueno et al., 2005).

A análise de Composição Centesimal foi realizada em equipamento Milkoscan 4000® (FOSS ELECTRIC A/S, HILLEROD, DINAMARCA, 2000), cujo princípio analítico baseia-se na absorção diferencial de ondas infravermelhas pelos componentes do leite (Bueno et al., 2005).

\section{Análise do proteinograma do leite}

A separação das proteínas foi realizada no equipamento Agilent 2100 Bioanalyzer (B) (Agilent Technologies, Waldbronn, Alemanha) utilizando o Agilent Protein Kit 230, capaz de identificar e quantificar proteínas com peso molecular entre 14 e $230 \mathrm{kDa}$. As análises foram realizadas no Laboratório Multiusuário de Biotecnologia do Instituto de Patologia Tropical e Saúde Pública da Universidade Federal de Goiás. O princípio analítico do ensaio utilizado para a separação das proteínas do soro das amostras de leite de vacas foi a eletroforese microfluídica em microchip (lab-on-a-chip) e os ensaios foram executados de acordo com o protocolo do fabricante, envolvendo o preparo dos reagentes, das amostras, dos microchips e programação das corridas no equipamento Agilent 2100 Bioanalyzer (Agilent Technologies). Cada corrida eletroforética durava aproximadamente 30 minutos.

As análises de eletroforese microfluídica tiveram padrões conhecidos por meio da corrida de proteínas purificadas: albumina (ALB), $\alpha$-lactalbumina bovina ( $\alpha$-LA), $\beta$-lactoglobulina ( $($-LG), lactoferrina (LF) e imunoglobulina G (IgG) (SigmaAldrich, St. Louis, EUA).

A identificação das proteínas do soro presentes nas amostras de leite de vacas foi determinada pela migração no gel, sendo observados os parâmetros de peso molecular e tempo de corrida no gel e no eletroferograma, produzidos através da fluorescência das proteínas e dos marcadores de peso molecular. Os picos obtidos pela eletroforese foram gerados automaticamente e captados pelo software.

Ao término de cada análise, procedeu-se a leitura do eletroferograma do Ladder para certificar a eficiência da análise e a robustez dos resultados, sendo observados: os marcadores de menor e maior peso molecular (Lower Marker e Upper Marker, respectivamente); os sete picos de proteínas e a base do eletroferograma que deveria ser limpa, lisa e sem ruídos.

A partir dos resultados da eletroforese microfluídica e da avaliação dos eletroferogramas foi possível identificar as proteínas do soro do leite. Para tanto, os picos de proteínas identificados nas amostras foram comparados com resultados de análise de eletroforese microfluídica de padrões de proteínas purificada e com padrões de proteínas identificadas da literatura (Hurley \& Theil, 2011; Che et al., 2015).

\section{Análise estatística}

Os valores referentes à CCS foram transformados em dados de logaritmo $(\log 10)$, uma vez que a CCS não possui 
distribuição normal. Foi utilizado um delineamento inteiramente ao acaso com cinco tratamentos com dez repetições, no qual cada grupo de variação da CCS foi considerado um tratamento. Os dados foram analisados utilizando a estatística descritiva e representações gráficas. A análise de variância (ANOVA) com um fator fixo foi utilizada para avaliar as modificações das proteínas do soro de leite em relação ao escore de células somáticas, seguida do teste post-hoc Mann-Whitney U (comparação 2 a 2) para a identificação das diferenças específicas nas variáveis em questão, seguindo o critério de significância estatística estabelecido $(\mathrm{p} \leq 0,05)$. Para avaliação dos dados de composição centesimal em função da CCS foi utilizado o Teste $\mathrm{T}$ de Student bicaudal.

Os programas utilizados para a realização das análises estatísticas foram SPSS- version 19.0 e software R (2009) (SOFTWARE R, 2010).

\section{Resultados e Discussão}

\section{Composição Centesimal e CCS}

As amostras de leite cru foram separadas em cinco grupos de acordo com os resultados de CCS obtidos nos ensaios analíticos. Os resultados da composição centesimal de cada escore de células somáticas (ECS) podem ser visualizados na Tabela 1. Segundo Machado et al. (2000), as principais alterações na composição do leite em casos de mastite subclínica são a diminuição nos teores de gordura, lactose e extrato seco e aumento nos teores de proteína.

Ao se compararem os resultados de composição centesimal entre os ECS, um a um, pelo teste estatístico T de Student, verificou-se um aumento significativo $(\mathrm{p} \leq 0,05)$ no valor do componente Proteína, notadamente entre os ECS 1 e 3,1 e 4 e 1 e 5. Resultados de estudos concernentes à alteração dos níveis de proteínas do soro em amostras de leite são controversos. Alguns autores afirmam que há aumento da concentração do teor de proteína de acordo com o aumento da CCS (Ma et al., 2000; Fernandes et al., 2007) . Outros, entretanto, observaram diminuição dos níveis de proteína em amostras de leite com altas contagens de CCS (Machado et al., 2000; Bueno et al., 2005). Ademais, há autores que não observaram variação significativa da proteína total (Zhang et al., 2015).

No presente estudo também foi possível observar diferença estatisticamente significativa $(\mathrm{p} \leq 0,05)$ nos resultados do componente Lactose quando se compararam os ECS 1 e 4 e 3 e 4. Tais resultados são corroborados por outros estudos, nos quais também foi possível observar redução dos níveis de lactose nas amostras de leite de vacas com mastite subclínica (Machado et al., 2000; Bueno et al., 2005).

Os resultados obtidos para o teor de proteínas do soro de leite e para o teor de lactose eram esperados, uma vez que a mastite, caracterizada como um processo inflamatório e infeccioso, altera a composição do leite. A permeabilidade dos vasos sanguíneos da glândula mamária é alterada, bem como a habilidade de síntese do tecido excretor (Machado et al., 2000). Vale ressaltar que a comparação realizada no presente estudo teve como base amostras controle, provenientes de leite de vacas sadias, ou seja, amostras de leite com CCS de até $100.000 \mathrm{cel} / \mathrm{mL}$ - ECS 1 e amostras de leite de vacas com mastite subclínica, ou seja, amostras com CCS acima de 200.000 cel/ mL - ECS 3, ECS 4 e ECS 5. 
Tabela 1. Análise descritiva da composição centesimal e escore de célula somática, Goiânia-GO, 2017.

\begin{tabular}{|c|c|c|c|c|}
\hline Variável & Escore & $\mathrm{N}^{\circ}$ de amostras & Média $(\%)$ & Desvio-Padrão \\
\hline \multirow{5}{*}{ Gordura } & 1 & 10 & 2,703 & 0,96 \\
\hline & 2 & 10 & 4,304 & 1,91 \\
\hline & 3 & 10 & 4,351 & 1,25 \\
\hline & 4 & 10 & 3,996 & 1,01 \\
\hline & 5 & 10 & 4,243 & 1,42 \\
\hline \multirow{5}{*}{ Proteína } & 1 & 10 & 2,942 & 0,32 \\
\hline & 2 & 10 & 3,115 & 0,61 \\
\hline & 3 & 10 & 3,478 & 0,42 \\
\hline & 4 & 10 & 3,668 & 0,63 \\
\hline & 5 & 10 & 3,35 & 0,50 \\
\hline \multirow{5}{*}{ Lactose } & 1 & 10 & 4,592 & 0,26 \\
\hline & 2 & 10 & 4,476 & 0,34 \\
\hline & 3 & 10 & 4,53 & 0,21 \\
\hline & 4 & 10 & 4,114 & 0,21 \\
\hline & 5 & 10 & 4,089 & 0,44 \\
\hline \multirow{5}{*}{ Extrato Seco Total } & 1 & 10 & 11,278 & 1,01 \\
\hline & 2 & 10 & 12,968 & 1,96 \\
\hline & 3 & 10 & 13,377 & 1,32 \\
\hline & 4 & 10 & 12,67 & 1,45 \\
\hline & 5 & 10 & 12,639 & 1,69 \\
\hline
\end{tabular}

Fonte: Autores (2021).

Durante a mastite, observa-se a diminuição da síntese celular e da síntese proteica. No entanto, o aumento da permeabilidade vascular do epitélio da glândula mamária, ocasionado pelo processo inflamatório, permite a passagem direta de proteínas do sangue para o leite. O aumento do teor de proteínas nas amostras de leite de vacas com mastite deve-se ao aumento dos níveis de proteínas de defesa, relacionadas à imunidade da glândula mamária, uma vez que as proteínas próprias do leite, como a caseína, diminuem. Assim, a quantidade de proteína nas amostras de leite de vacas com mastite pode aumentar, principalmente em função das proteínas provenientes da corrente sanguínea que podem compensar as perdas provocadas pelo decréscimo da síntese proteica da glândula mamária, corroborando aos achados deste estudo (Gigante et al., 2008).

De acordo com Gigante et al. (2008), a alteração nos níveis de lactose também ocorre em amostras de leite com altas CCS devido à alteração do epitélio, que nesta condição não regula as trocas entre o lúmen alveolar e a circulação sanguínea, permitindo o livre trânsito da lactose e sais. A elevação da concentração de sais, como sódio e cloro, desencadeia, provavelmente, a elevação da pressão osmótica do leite, o que leva à redução da concentração da lactose. Outras causas da diminuição da concentração da lactose seriam resultado da síntese diminuída deste carboidrato pela glândula mamária em função da mastite; da utilização da lactose como fonte de energia pelos patógenos intramamários; e da perda de lactose da glândula para a corrente sanguínea, devido ao aumento da permeabilidade da membrana, que separa o leite do sangue, levando à excreção da mesma na urina (Machado et al., 2000).

\section{Identificação das proteínas do soro de leite em função dos Escores de Células Somáticas (ECS)}

A utilização de métodos com capacidade para separação, identificação e quantificação das proteínas fornecem informações importantes sobre as propriedades físico-químicas do leite que podem ser influenciadas por diferentes sistemas de produção leiteiros (Costa et al., 2014). Desta forma, a tecnologia de eletroforese microfluídica lab-on-a-chip vem sendo 
utilizada em diversos estudos com o intuito de verificar a eficiência dessa técnica na avaliação da distribuição de diferentes frações proteicas do leite (Anema, 2009; Santos et al., 2013; Costa et al., 2014).

$\mathrm{O}$ método de eletroforese microfluídica tem sido relatado como uma boa alternativa para o método tradicional de Eletroforese em gel de poliacrilamida (SDS-PAGE). Os estudos de Anema (2009) e Costa et al. (2014) tiveram como objetivo determinar a eficiência da técnica de eletroforese microfluídica quando utilizada para separação e quantificação das proteínas maiores/ alta abundância do leite em comparação à técnica SDS-PAGE. Ambos os autores concluíram que a técnica de eletroforese microfluídica lab-on-a-chip constitui uma alternativa prática e rápida para a separação simultânea das proteínas a grande abundância do soro do leite.

A eletroforese microfluídica também foi utilizada com sucesso em estudos para identificação de fraudes em leite de cabra por leite de vacas (Santos et al., 2013; Meurer, 2014; Santos et al., 2018) a partir da identificação das frações proteicas da Kappa-Caseína no leite de vaca. Em outro estudo, foi possível realizar a caracterização proteica do leite de vacas de raças regionais, raça Curraleiro Pé-Duro e raça Pantaneira, do Centro-Oeste brasileiro (Sola, 2015).

Tais estudos corroboram com os resultados aqui obtidos, uma vez que demonstram a eficiência da metodologia empregada para separação, identificação e quantificação das proteínas do soro do leite de vacas.

No presente estudo, a análise de eletroforese microfluídica foi realizada em amostras de leite fluido desnatado, sem o procedimento de coagulação das proteínas e separação do soro, ao contrário dos procedimentos realizados pelos demais autores citados. A identificação com eficiência das proteínas do soro de leite nas amostras utilizadas no presente estudo indica uma alternativa para o preparo de amostras e a realização de eletroforese microfluídica, otimizando o tempo de análise.

\section{Perfil de proteínas expressas nas amostras de leite de acordo com cada grupo de Escore de Células Somáticas}

Ao comparar a média da concentração das proteínas expressas nas amostras de leite de cada grupo de ECS (Tabela 2), foi possível observar que não há evidência estatística $(\mathrm{p} \geq 0,05)$ de que a concentração total das proteínas expressas em um grupo de ECS seja diferente da concentração das proteínas expressas em outro grupo de ECS. A apresentação gráfica da variação da concentração total de proteínas dos grupos de ECS pode ser visualizada na Figura 1.

Apesar do valor total da concentração das proteínas dos ECS não apresentar diferença estatística, foi possível observar que, a partir da análise da variável Concentração (Tabela 2), a concentração total das proteínas das amostras de leite provenientes de vacas com mastite subclínica (ECS 3 - 5) revelou-se numericamente menor que a concentração das proteínas das amostras dos ECS 1 e 2. No entanto, foi possível observar um aumento do número de proteínas identificadas nas amostras de leite provenientes de vacas com mastite subclínica, uma vez que as amostras dos ECS 3, 4 e 5 apresentaram 122, 119 e 136 proteínas, respectivamente; enquanto que nas amostras do ECS 1 foi possível identificar 107 proteínas, e nas do ECS 2, 105 proteínas. Os eletroferogramas das amostras de cada ECS podem ser visualizados na Figura 1.

Das análises dos resultados obtidos (Tabela 2) pode-se constatar que, por ocasião de uma infecção intramamária, ocorreu o aumento do número de proteínas na glândula mamária e, consequentemente, no leite, no entanto, observou-se a diminuição da concentração total das proteínas presentes no leite. Isso pode ser devido ao aumento do número das proteínas de defesa, ou seja, durante a mastite, uma grande quantidade de diferentes proteínas de defesa, como as proteínas de fase aguda (PFA), peptídeos antimicrobianos (PAMs), imunoglobulinas, entre outras, foram sintetizadas a fim de eliminar a infecção na glândula mamária (Addis et al., 2013). 
Tabela 2. Análise descritiva da diferença de concentração das proteínas totais expressas nas amostras em função dos Escores de Célula Somática, Goiânia-GO, 2017.

\begin{tabular}{ccccccc}
\hline & Escore & $\begin{array}{c}\mathrm{N}^{\circ} \text { proteínas } \\
\text { identificadas }\end{array}$ & Média & Desvio-padrão & $\begin{array}{c}\text { Log (concentração) } \\
\text { Média }\end{array}$ & $\begin{array}{c}\text { Desvio- } \\
\text { padrão }\end{array}$ \\
\hline & 1 & 107 & 2486,44 & 7908,40 & 2,49 & 0,97 \\
Concentração & 2 & 105 & 1267,17 & 1788,52 & 2,54 & 0,85 \\
(ng/uL) & 3 & 122 & 1399,00 & 2435,86 & 2,52 & 0,88 \\
& 4 & 119 & 1120,30 & 1423,50 & 2,58 & 0,78 \\
& 5 & 136 & 946,63 & 1092,32 & 2,54 & 0,76 \\
\hline
\end{tabular}

Fonte: Autores (2021).

Figura 1 - Eletroferogramas de amostras de leite de vacas com ECS de 1 a 5. Sendo Fu: Unidade de Fluorescência e kDa: quilo Dalton.
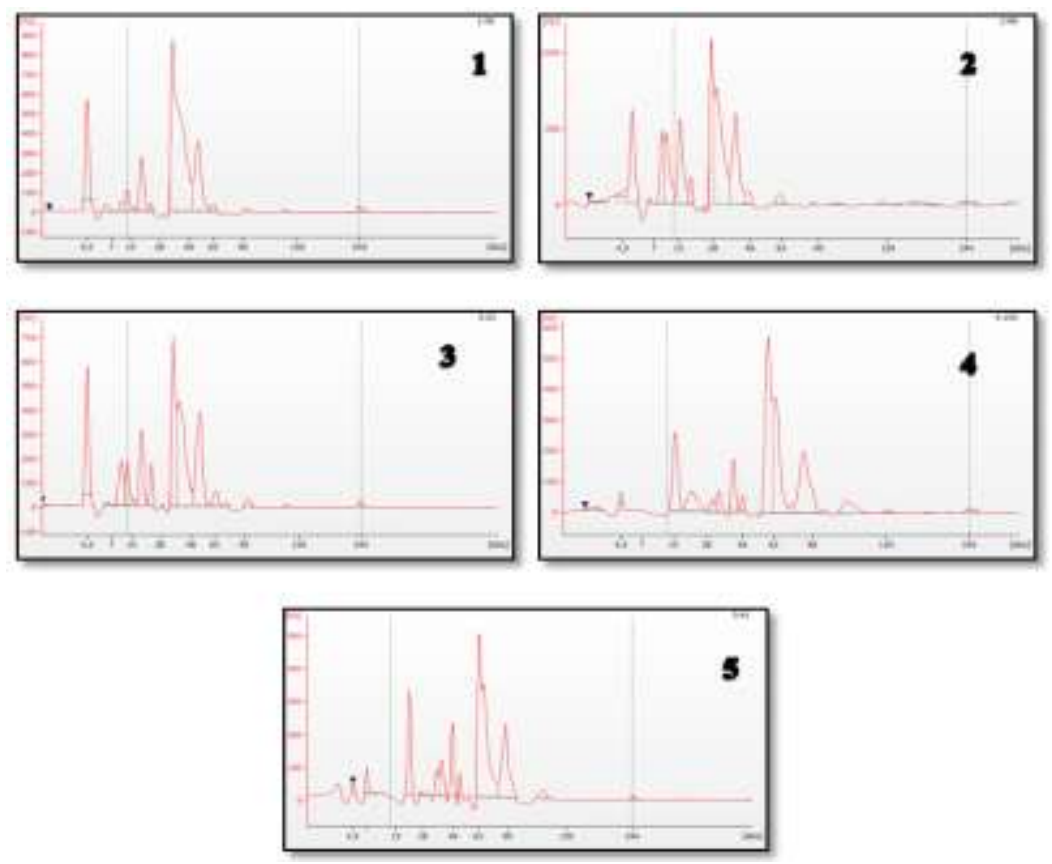

Fonte: Autores (2021).

Amostras de leite de vacas com mastite possuem maior diversidade de proteínas, no entanto, são proteínas de pequena abundância, uma vez que são proteínas de defesa e com atividades antimicrobianas e inflamatórias. Já amostras de leite de vacas sem mastite (ECS 1 e 2) possuem grande quantidade de proteínas de alta abundância, como $\alpha$-LA e $\beta$-LG. Nesse sentido, o aumento do número de proteínas e a diminuição numérica da concentração total de proteínas podem estar relacionados ao estado sanitário e inflamatório das glândulas mamárias das vacas que originaram as amostras (Santos et al., 2018).

Guerrero et al. (2015) obtiveram resultado semelhante ao presente estudo, ao verificar um aumento na produção de peptídeos derivados de proteínas em amostras de leite de vacas com mastite subclínica quando comparado com as amostras de leite de vacas com mastite clínica. Em outro estudo, Mansor et al. (2013) também obtiveram resultados semelhantes, ao observar um aumento da concentração dos peptídeos em amostras de leite de vacas com mastite em relação às amostras de leite de vacas sadias. 


\section{Avaliação descritiva por Escore de Células Somáticas e proteínas}

Na avaliação descritiva da variável "Concentração" das proteínas do leite foi possível observar diferenças nos valores das concentrações em função do ECS (Tabela 3). Os resultados da variável "concentração" da proteína $\alpha$-LA obtidos de amostras que apresentaram ECS 1,2 e 3 foram estatisticamente diferentes $(p \leq 0,05)$ dos resultados obtidos das amostras de ECS 5. Na avaliação da proteína IgG foi possível observar que as amostras de ECS 4 e 5 apresentaram concentrações estatisticamente diferentes $(\mathrm{p} \leq 0,05)$ das amostras dos ECS 1,2 e 3. Para a proteína LF, foi possível observar diferença estatística $(p \leq 0,05)$ entre os resultados obtidos das amostras de ECS 1 e 5 (Tabela 3 ).

Tabela 3. Análise descritiva da variável concentração das proteínas identificadas nas amostras de leite, Goiânia-GO, 2017.

\begin{tabular}{|c|c|c|c|c|c|c|}
\hline Proteína* & Variável & escore & $\mathrm{N}$ & $\begin{array}{c}\text { Média da } \\
\text { concentração }\end{array}$ & Desvio-padrão & $* *$ \\
\hline \multirow[t]{5}{*}{$\alpha-\mathrm{LA}$} & Concentração & 1 & 10 & 3298.69 & 1037.83 & $\mathrm{~A}$ \\
\hline & (ng/uL) & 2 & 8 & 1460.19 & 1472.79 & A \\
\hline & & 3 & 10 & 1169.92 & 1340.94 & A \\
\hline & & 4 & 9 & 1048.06 & 876.71 & $a, a b$ \\
\hline & & 5 & 10 & 436.96 & 909.20 & $a b, b$ \\
\hline \multirow[t]{5}{*}{ ALB } & Concentração & 1 & 7 & 2534.34 & 4931.58 & A \\
\hline & (ng/uL) & 2 & 8 & 1112.48 & 1446.05 & A \\
\hline & & 3 & 9 & 767.49 & 1236.31 & A \\
\hline & & 4 & 6 & 2306.43 & 859.98 & A \\
\hline & & 5 & 10 & 1952.49 & 655.56 & A \\
\hline \multirow{5}{*}{$\begin{array}{c}\beta-\mathrm{LG}- \\
\text { pico } 1\end{array}$} & Concentração( & 1 & 9 & 1470.44 & 2478.91 & A \\
\hline & ng/uL) & 2 & 10 & 1089.41 & 1193.30 & A \\
\hline & & 3 & 10 & 1574.81 & 1736.43 & A \\
\hline & & 4 & 10 & 1303.45 & 1138.07 & A \\
\hline & & 5 & 10 & 379.90 & 393.11 & A \\
\hline \multirow{5}{*}{$\begin{array}{c}\beta-\mathrm{LG}- \\
\text { pico } 2\end{array}$} & Concentração( & 1 & 10 & 734.57 & 1259.18 & $\mathrm{~A}$ \\
\hline & ng/uL) & 2 & 10 & 612.34 & 537.59 & A \\
\hline & & 3 & 9 & 539.24 & 572.77 & A \\
\hline & & 4 & 10 & 333.23 & 263.03 & A \\
\hline & & 5 & 10 & 352.01 & 185.80 & A \\
\hline \multirow{5}{*}{$\begin{array}{c}\text { IgG } \\
\text { cadeia } \\
\text { leve }\end{array}$} & Concentração & 1 & 10 & 1379.36 & 693.31 & A \\
\hline & (ng/uL) & 2 & 10 & 1199.12 & 174.66 & A \\
\hline & & 3 & 10 & 3432.22 & 2492.01 & A \\
\hline & & 4 & 10 & 3606.30 & 3770.01 & B \\
\hline & & 5 & 10 & 4987.57 & 3329.29 & B \\
\hline \multirow{4}{*}{$\begin{array}{c}\text { IgG } \\
\text { cadeia } \\
\text { pesada }\end{array}$} & Concentração & 1 & 10 & 1265.75 & 928.28 & $\mathrm{~A}$ \\
\hline & (ng/uL) & 2 & 9 & 2489.59 & 1754.24 & A \\
\hline & & 3 & 10 & 2452.98 & 476.70 & A \\
\hline & & 4 & 9 & 2588.91 & 1170.26 & $\mathrm{~B}$ \\
\hline
\end{tabular}




\begin{tabular}{ccccccc} 
& & 5 & 10 & 3394.80 & 3107.15 & $\mathrm{~B}$ \\
\hline IgM & Concentração & 1 & 3 & 1921.93 & 859.24 & $\mathrm{~A}$ \\
& $(\mathrm{ng} / \mathrm{uL})$ & 2 & 3 & 1383.07 & 1154.64 & $\mathrm{~A}$ \\
& & 3 & 2 & 1957.85 & 200.32 & $\mathrm{~A}$ \\
& & 4 & 4 & 2027.03 & 580.19 & $\mathrm{~A}$ \\
& & 5 & 9 & 1745.37 & 648.83 & $\mathrm{~A}$ \\
\hline LF & Concentração & 1 & 10 & 83.83 & 200.76 & $\mathrm{a}, \mathrm{ab}$ \\
& $(\mathrm{ng} / \mathrm{uL})$ & 2 & 9 & 170.02 & 209.05 & $\mathrm{Ab}$ \\
& & 3 & 10 & 268.55 & 287.15 & $\mathrm{Ab}$ \\
& & 4 & 9 & 1009.96 & 1525.96 & $\mathrm{Ab}$ \\
& & 5 & 10 & 709.83 & 1501.06 & $\mathrm{ab}, \mathrm{b}$ \\
\hline LPO & Concentração & 1 & 4 & 75.45 & 40.95 & $\mathrm{~A}$ \\
& $(\mathrm{ng} / \mathrm{uL})$ & 2 & 5 & 960.78 & 2042.86 & $\mathrm{~A}$ \\
& & 3 & 10 & 410.27 & 1112.54 & $\mathrm{~A}$ \\
& & 4 & 8 & 1906.41 & 3574.70 & $\mathrm{~A}$ \\
& & 5 & 6 & 3065.52 & 7361.42 & $\mathrm{~A}$ \\
\hline
\end{tabular}

$* \alpha$-LA $=\alpha$-lactoalbumina; ALB= albumina; $\beta$ - LG - pico $1=\beta$ - lactoglobulina; $\operatorname{IgG}=$ imunoglobulina $\mathrm{G} ; \operatorname{IgM}=$ imunoglobulina $\mathrm{M} ; \mathrm{LF}=$ lactoferrina; $\mathrm{LPO}=$ lactoperoxidase

**A diferença estatística entre as médias está representada por letras diferentes. Letras iguais não apresentam diferença estatística (valor $\mathrm{p} \geq 0,05$ ).

Fonte: Autores (2021)

Ao avaliar a proteína $\alpha$-LA observa-se que ocorre diminuição na concentração desta proteína em função do ECS, ou seja, a concentração da $\alpha$-LA em amostras de leite de vacas sadias no ECS 1 , foi maior que a concentração desta mesma proteína em amostras de leite de ECS 3, 4 e 5, oriundos de vacas com mastite subclínica. No presente estudo, a concentração da proteína $\alpha$-LA apresentou resultados estatisticamente diferentes (valor $p \leq 0,05$ ) quando se comparou os ECS 1,2 e 3 com ECS 5.

Relativamente a proteína $\beta$-LG, sabe-se que sua concentração diminui à medida que se tem um quadro indicativo de IIM. Em vacas sadias é a proteína do soro de leite de maior concentração, sendo seguida pela $\alpha$-LA. Devido às suas propriedades de ligação, muitos estudos indicam sua função como importante papel no transporte de retinol, ácidos graxos ou vitamina A (Rocha et al., 1996; Brownlow et al., 1997; LI et al., 2014).

Os resultados obtidos para $\alpha$-LA e $\beta$-LG eram esperados, uma vez que ambas são as proteínas do soro de leite de maior abundância em leite de vacas sadias. Os resultados obtidos no presente estudo para as duas proteínas são semelhantes aos obtidos por Hogarth et al. (2004), Li et al. (2014), Thomas et al. (2016). Esses autores também observaram diminuição dos teores das proteínas $\alpha$-La e $\beta$-LG em amostras de leite de vacas com mastite.

Segundo Guerrero et al. (2015), a diminuição dos níveis das proteínas $\alpha$-LA e $\beta$-LG pode ser decorrente tanto do aumento da atividade de proteases no leite de vacas com mastites, quanto da diminuição na síntese dessas proteínas durante as mastites, ou seja, do aumento da síntese de proteínas de defesa.

$\mathrm{Na}$ avaliação da proteína ALB, apesar de não haver diferença estatística significativa entre os resultados e concentrações dessa proteína em função dos ECS, foi possível observar uma diminuição numérica de concentração à medida em que o ECS aumentou. Sadek et al. (2017) também observaram diminuição na concentração da ALB em amostras de leite de vacas com mastite subclínica quando comparadas com amostras de leite de vacas sadias. 
De acordo com Tothova et al. (2014), a diminuição de concentração de ALB está relacionada com a resposta da fase aguda (RFA). Segundo esses autores, durante a RFA a demanda por aminoácidos para síntese das proteínas de fase aguda (PFA) positivas é aumentada, com isso, ocorre um rearranjo da síntese proteica hepática e priorização da síntese de PFA positivas. Como a ALB é uma proteína de fase aguda negativa, a síntese é diminuída e os aminoácidos são direcionados para a síntese de PFA positivas.

$\mathrm{Na}$ avaliação da proteína IgG foi possível observar um aumento de suas concentrações em função do aumento dos ECS. Musayeva et al.(2016) também observaram aumento na concentração de IgG nas amostras de leite de vacas com mastite subclínica, ou seja, em amostras de leite com CCS maior que 200.000cel/mL. O aumento da concentração de Imunoglobulinas pode ser em decorrência do aumento da permeabilidade dos vasos sanguíneos do úbere por ocasião da infecção. O aumento da concentração das Imunoglobulinas indica atividade da resposta imune (Koskinen et al., 2009; Musaeyva et al., 2016)

Quando se comparam os resultados obtidos para a concentração da proteína LF em função dos grupos de ECS, os dados do presente estudo são corroborados por diversos outros estudos ( $\mathrm{Li}$ et al., 2014; Zbinden et al., 2014; Chopra et al., 2015; Kawai et al., 2015; Musayeva et al., 2016; Thomas et al., 2016; Sadek et al., 2017) Todos estes autores observaram aumento na concentração da proteína LF de acordo com a ocorrência de mastites, ou seja, vacas com IIMs apresentaram concentração da LF no leite maior que em vacas sadias.

A proteína LF integra o sistema imune inato da glândula mamária de vacas, sendo classificada como um peptídeo antimicrobiano. Sua principal função antimicrobiana está relacionada à capacidade de ligação aos íons de ferro livre no ambiente. Assim, os íons ferros são sequestrados, tornando-se indisponíveis para utilização no metabolismo microbiano, o que leva à inibição do desenvolvimento de bactérias, bolores e fungos. Outros mecanismos bactericidas da LF estão relacionados à possibilidade de aderência à parede bacteriana, ocasionando injúria celular, levando à morte ou diminuição da resistência ( Pereyra et al., 2014; Kawai et al., 2015; Mao et al., 2015; Hisaieda et al., 2016).

Os resultados de CCS vêm sendo correlacionados positivamente com mastites subclínicas e concentração de lactoferrina (HUANG et al., 2010; Zabolewicz et al., 2014; Chopra et al., 2015). De acordo com Chopra et al. (2015), diferentes concentrações de LF são encontradas quando se comparam resultados de amostras de leite de vacas sadia com amostras de leite de vacas com mastite clínica e subclínica, sendo observado uma maior expressão genética do gene da LF em vacas com mastites. Devido ao importante papel desempenhado pela LF na saúde da glândula mamária, essa proteína pode ser considerada um biomarcador promissor para mastite e potencial candidata na seleção animal para resistência de mastites (Smolenski et al., 2014; Chopra et al., 2015; Mao et al., 2015).

Relativamente à proteína IgG, observou-se um aumento estatisticamente significativo $(\mathrm{p} \leq 0,05)$ em sua concentração em amostras de leite de vacas com mastite subclínica, pertencente aos ECS 4 e 5 (CCS acima de 500.000 cel $/ \mathrm{mL}$ ) quando comparadas com amostras de leite de vacas sadias (CCS até $200.000 \mathrm{cel} / \mathrm{mL}$ ) e com amostras de leite de vacas com mastite subclínica de intensidade leve (CCS entre 200 e $500.000 \mathrm{cel} / \mathrm{mL}$ ). A IgG é um componente do sistema imune da glândula mamária e auxilia na remoção de substâncias não próprias aos organismos, além de exibir atividade antimicrobiana em leite de vacas contra bactérias patogênicas. Em casos de infecções pode-se observar um aumento na concentração de IgG em amostras de leite de vacas. Apesar do aumento da concentração ter sido relacionado à transferência da imunoglobulina do sangue para a glândula mamária, a alteração dos níveis da proteína $\operatorname{IgG}$ se dá por estímulo à síntese proteica local devido a presença do patógeno (Harmon et al., 1976; Ostensson \& Lun, 2008; Hurley \& Theil, 2011).

A proteína IgG é conhecida por fazer parte da imunidade passiva, como proteína de defesa, transferida do leite colostral ao bezerro. Auxilia, juntamente com a proteína LF, na proteção do neonato contra infecções, até que consiga desenvolver seu próprio sistema imunológico (Campanella et al., 2009; Hurley \& Theil, 2011). A elevação da concentração da IgG em amostras de leite de vacas com mastite vem sendo observada em outros estudos (Harmon et al., 1976; Ostensson \& 
Lun, 2008). Apesar de a proteína LF ser considerada, por outros autores, um biomarcador potencial para mastite, os resultados obtidos no presente estudo demonstram que a proteína IgG pode ser também um excelente marcador. No presente estudo verificou-se que a diferença nos níveis de concentração da proteína IgG foi observada em amostras de leite de vacas com mastite subclínica com CCS acima de $500.000 \mathrm{cel} / \mathrm{mL}$, enquanto a diferença na concentração nos níveis da proteína LF foi observada em amostras de leite de vacas com mastite subclínica com CCS acima de 1.000 .000 cél $/ \mathrm{mL}$. Infere-se, portanto, que a IgG é um marcador mais sensível que a proteína LF.

$\mathrm{Na}$ avaliação dos resultados da concentração da proteína LPO (Tabela 3), pode-se observar um aumento numérico em sua concentração em função do aumento do ECS, ou seja, as amostras de leite de vaca com mastite subclínica, com resultado de CCS acima de $500.000 \mathrm{cel} / \mathrm{mL}$, apresentaram as maiores concentrações de LPO. Os estudos de Kawai et al. (2015); Zhang et al. (2015) corroboram os resultados obtidos neste estudo. Assim como a LF, a LPO também é classificada como um peptídeo antimicrobiano, tendo papel importante no Sistema Imune Inato da glândula mamária.

Os dados do presente estudo revelaram que, ao se comparar resultados de amostras de leite de vacas sadias e resultados de amostras de leite de vacas com mastite subclínica, a diferença não está na expressão nem na produção das proteínas, mas sim em suas concentrações em função do status sanitário da glândula mamária. Ou seja, é possível identificar a maioria das proteínas em todas as amostras de leite analisadas, no entanto, a diferença está no resultado de suas concentrações em função dos ECS.

\section{Considerações Finais}

Em amostras de leite com altas CCS, não foram observadas alterações significativas na concentração de proteínas. As proteínas de alta abundância do soro de leite tiveram sua concentração diminuída em função da severidade da infecção intramamária (alta CCS) enquanto as proteínas de defesa, como Lactoferrina, Lactoperoxidase, IgG e IgM tiveram aumento numérico visual em suas concentrações ao se comparar amostras de leite de vacas com mastite subclínica (alta CCS) e amostras de leite de vacas sadias.

As proteínas Lactoferrina e IgG constituem alvos em potencial para identificar vacas com mastite subclínica a partir de amostras de leite, podendo ser consideradas biomarcadores.

A técnica de eletroforese microfluídica lab-on-a-chip, utilizada no presente estudo se mostrou eficiente na identificação, discriminação e quantificação de proteínas do soro lácteo.

\section{Referências}

Addis, M.F., Pisanu, S., Marogna, G., Cubeddu, T., Pagnozzi, D., Cacciott\& o, C., Campesi, F., Schianchi, G., Rocca, S., \& Uzzau, S. (2013). Production and release of antimicrobial and imune defense proteins by mammary ephitelial celles following Streptococcus uberis infection of sheep. Infet Immun., 81 (9): 3182-97.

Akerstedt, M., Forsbäck, L., Larsen, T., \& Svennersten-Sjaunja, K. (2011). Natural variation in biomarkers indicating mastitis in healthy cows. J Dairy Res, 78 (1): 88-96.

Anema, S. G. (2009). The use of 'Lab-on-a-chip' microfluidic SDS electrophoresis technology for the separation and quantification of milk proteins. Int Dairy J, 19: 198-204.

Bislev, S. L., Deutsch, E. W., Sun, Z., Farrah, T., Aebersold, R., Moritz, R. L., Bendixen, E., \& Codrea, M. C. (2012). A bovine peptide atlas of milk and mammary gland proteomes. Proteomics, 12 (18): 2895-9.

Brownlow, S., Morais Cabral, J. H., Cooper, R., \& Flower, D. R. (1997). Bovine $\beta$-lactoglobulin at 1.8 A resolution - still an enigmatic lipocalin. Structure, 5: 481-95.

Bueno, V. F. F., Mesquita, A. J., Soares, N. E., Liveira, A. N., Oliveira, J. P., Neves, R. B., Mansur, J. R. G., \& Thomaz, L. W. (2005). Contagem celular somática: relação com a composição centesimal do leite e período do ano no Estado de Goiás. Ciência Rural, 35 (4): $848-54$.

Campanella, L., Martini, E., Pintore, M., \& Tomassetti, M. (2009). Determination of lactoferrina and immunoglobulin g in animal milks by new immunosensors. Sensors (Basel), 9 (3): 2202-21. 
Chopra, A., Gupta, I. D., Verma, A., Chakravarty, A. K., \& Vohra, V. (2015). Lactoferrin gene promoter variants and their association with clinical and subclinical mastitis in indigenous and crossbred cattle. Pol J Vet Sci., 18(3):465-71.

Che, H.X., Tian, B., Bai, L.N., Cheng, L.M., Liu, L.L., Zhang, X.N., Jiang, Z.M., \& Xu, X.X. (2015). Development of a test strip for rapid detection of Lactoperoxidase in raw milk. J Zhejiang Univ Sci B., 16(8):672-9.

Costa, F. F., Brito, M. A. V. P., Furtado, M. A. M, Martins, M. F., Oliveira, M. A. L., Barra, P. M. C., Garrido, L. A., \& Santos, A. S. O. (2014). Microfluidic chip electrophoresis investigation of major milk proteins: study of buffer effects and quantitative approaching. Anal Methods, 6: $1666-73$.

Fernandes, A. M., Oliveira, C. A. F., \& Lima, C. G.(2007). Effects os fomatic cell counts in milk on physical and chemical characteristics of yoghurt. Int Daory J. 17: 111-5

Gigante, M. I., \& Costa, M. R. (2008). Influência das células somáticas nas propriedades tecnológicas do leite e derivados. In: Barbosa SBP, Batista AMV, Monardes H. III Congresso Brasileiro de Qualidade do Leite. Recife: CCS Gráfica e Editora. 2008, 1: 161-74.

Guerrero, A., Dallas, D. C., Contreras, S., Bhandari, A., Cánovas, A., Islas-Trejo, A., Medrano, J. F., Parker, E. A., Wang, M., Hettinga, K., Chee, S., German, J. B., Barile, D., \& Lebrilla, C. B. (2015). Peptidomic analysis of healthy and subclinically mastitic bovine milk. Int Dairy J. 46:46-52.

Harmon, R.J. (1994). Symposium: Mastitis and genetic evaluation for somatic cell count—physiology of mastitis and factors affecting somatic cell counts. $J$ Dairy Sci,77 (7): 2103-12.

Harmon, R. J., Schanbacher, F. . L., Ferguson, L. C., \& Smith, K. L. (1976). Changes in lactoferrin, immunoglobulin G, bovine serum albumin, and alphalactalbumin during acute experimental and natural coliform mastitis in cows. Infect Immun., 13: 533-42.

Hisaeda, K., Koshiishi, T., Watanabe, M., Miyake, H., Yoshimura, Y., \& Isobe, N. (2016). Change in viable bacterial count during preservation of milk derived from dairy cows with subclinical mastitis and its relationship with antimicrobial components in milk. J Vet Med Sci.,78 (8): $1245-50$.

Hogarth, C.J., Fitzpatrick, J.L., Nolan, A.M., Young, F.J., Pitt, A., \& Eckersall, P.D. (2004). Differential protein composition of bovine whey: a comparison of whey from healthy animals and from those with clinical mastitis. Proteomics, (7):2094-100.

Huang, J., Wang, H., Wang, C., Li, J., Li, Q., Hou, M., \& Zhong, J. (2010). Single nucleotide polymorphisms, haplotypes and combined genotypes of lactoferrina gene and their associations with mastitis in Chinese Holstein cattle. Mol Biol Rep., 37 (1): $477-83$.

Hurley, W. L., \& Rejman, J. J. (1993). Bovine lactoferrina in involuting mammary tissue. Cell Biol Int., 17 (3): $283-9$.

Hurley, W.L., Theil, P.K. (2011) Perspectives on immunoglobulins in colostrum and milk. Nutrients., 3 (4): $442-74$.

Kawai, K., Korematsu, K., Akiyama, K., Okita, M., Yoshimura, Y., \& Isobe, N. (2015). Dynamics of lingual antimicrobial peptide, lactoferrina concentrations and Lactoperoxidase activity in the milk of cows treated for clinical mastitis. Anim Sci J., 86 (2): 153-8.

Koskinen, M. (2009). Analytical specificity and sensitivity of a real-time polymerase chain reaction assay for identification of bovine mastitis pathogens. $J$ Dairy Sci, 92: 952-959.

Li, X., Ding, X. Z., Wan,Y. L., Liu,Y. M., \& Du, G. Z. (2014). Comparative proteomic changes of differentially expressed whey proteins in clinical mastitis and healthy yak cows. Genet Mol Res., 13(3):6593-601.

Ma, Y., Ryan, C., Barbano, D. M., Galton, D. M., Rudan, M.A., \& Boor, K. J. (2000). Effects of Somatic Cell Cout on Quality and Shelf-life os pasteurized fluid milk. J Dairy Sci., 83: 264-74.

Machado, P. F., Pereira, A.R., \& Sarries, G. A. (2000). Composição do leite de tanques de rebanhos brasileiros distribuídos segundo sua contagem de células somáticas. Rev Bra Zootec. 29 (6), 1883-6.

Mansor, R., Mullen, W., Albalat, A., Zerefos, P., Mischak, H., Barrett, D. C., Biggs, A., \& Eckersall, P. D. (2013). A peptidomic approach to biomarker discovery for bovine mastitis. J Proteomics, 85: 89-98.

Mao, Y., Zhu, X., Xing, S., Zhang, M., Zhang, H., Wang, X., Karrow, N., Yang, L., \& Yang, Z. (2015). Polymorphisms in the promoter region of the bovine lactoferrina gene influence milk somatic cell score and milk production traits in Chinese Holstein cows. Res Vet Sci., 103:107-12.

Meurer, V.M. Estudo comparativo entre as técnicas de eletroforese em gel de poliacrilamida ureia-page e lab-on-a-chip para detecção de fraude do leite de cabra pela adição de leite bovino. [Dissertação]. Juiz de Fora: Universidade Federal de Juiz de Fora, Faculdade de Farmácia, 2014.

Musayeva, K., Sederevičius, A., Želvytė, R., Monkevičienė, I., Beliavska-Aleksiejūnė, D., \& Kerzienė, S. (2016). Concentration of lactoferrina and immunoglobulin G in cows' milk in relation to health status of the udder, lactation and season. Pol J Vet Sci., 19 (4): $737-44$.

Ostensson, K., \& Lun, S. (2008). Transfer of immunoglobulins through the mammary endothelium and epithelium and in the local lymphnode of cows during the initial response after intramammary challenge with E. coli endotoxin. Acta Vet Scand., 50: 1-10.

Pereyra, E. A., Dallard, B. E., \& Calvinho, L. F. (2014). Aspects of the innate immune response to intramammary Staphylococcus aureus infections in cattle. Rev Argent Microbiol., 46 (4): 363-75.

Pyorala, S., Hovinen, M., Simojoki, H., Fitzpatrick, J., Ecksersall, P. D., \& Orro, T. (2011). Acute phase proteins in milk in naturally acquired bovine mastitis caused by different pathogens. Vet Rec., 168 (20): 535.

Reinhardt, T. A., Sacco, R. E., Nonnecke, B. J., \& Lippolis, J. D. (2013). Bovine milk proteome: Quantitative changes in normal milk exosomes, milk fat globule membranes and whey proteomes resulting from Staphylococcus aureus mastitis. J Proteomics, 26 (82): 141-54. 
Rocha, T. L., Brownlow, S., Saddler, K. N., \& Fothergill-Gilmore, L. A. (1996). New crystal form of $\beta$-lactoglobulin. J. Dairy Res, 63: 575-84.

Rodha, A. D., Pantoja, J. C. (2012). Using mastitis records and somatic cell count data. The Vet Clin North Am Food Anim Pract, 28 (2): $347-361$.

Sadek, K., Saleh, E., Ayoub, M.(2017). Selective, reliable blood and milk bio-markers for diagnosing clinical and subclinical bovine mastitis. Trop Anim Health Prod., 49 (2): 431-7.

Santos, A. S. O., Meurer, V. M., Jesus, D. C., Pinto, I. S. B., Egito, A. S., Furtado, M. A. M., \& Martins, M. F. (2013). Uso da tecnologia de eletroforese microfluídica "lab-on-a-chip" para análises das proteínas do leite em fraudes de leite caprino com leite bovino. Vet. e Zootec., 20 (2 Supl 1): 86-7.

Santos, A. S. D. O., Meurer, V. M., Costa, F. F., De Paiva, I. M., Fogaça, G. N., Do Egito, A. S., \& Martins, M. F. (2018). Major goat milk protein: separation and characterization by "lab-on-a-chip" microfluidic electrophores. Boletim Do Centro de Pesquisa de Processamento de Alimentos, 35(2), 1-13.

Schepers, A. J., Lam. T. J. G. M., Schukken, Y. H., Wilmink, J. B. M., \& Hanekamp, W. J. A. (1997) Estimation of variance components for somatic cell counts to determine thresholds for uninfected quarters. J Dairy Sci, 80 (80): 1833-40.

Smolenski, G. A., Broadhurst, M. K., Stelwagen, K., Haigh, B. J., \& Wheeler, T. T. (2014). Host defence related responses in bovine milk during an experimentally induced Streptococcus uberis infection. Proteome Sci., 12 (19): 1-14.

Smolenski, G., Haines, S., Kwan, F. Y. S., Bond, J., Farr, V., Davis, S. R., Stelwagen, K., \& Wheeler, T. T. (2007). Characterisation of host defence proteins in milk using a proteomic approach. J Proteome Res, 6 (1): 207-15.

Software, R. IBM Corp. Released 2010. IBM SPSS Statistics for Windows, Version 19.0. Armonk, IBM Corp.

Sola, M.C. (2015). Características do leite e sanidade da glândula mamária de bovinos curraleiro pé-duro e pantaneiro. [Tese]. Universidade Federal de Goiás, Escola de Veterinária e Zootecnia, 2015.

Thomas, F .C., Mullen, W., Tassi, R., Ramírez-Torres, A., Mudaliar, M., McNeilly, T. N., Zadoks, R. N., Burchmore, R., \& David Eckersall, P. (2016). Mastitomics, the integrated omics of bovine milk in an experimental model of Streptococcus uberis astitis: 1 . High abundance proteins, acute phase proteins and peptidomics. Mol Biosyst., 12 (9): 2735-47.

Tothova, C., Nagy, O., \& Kovac, G. (2014). Acute phase proteins and their use in the diagnosis of diseases in ruminants: a review. Veterinarni Medicina, 59 (4): $163-80$.

Zabolewicz, T., Barcewicz, M., Brym, P., Puckowska, P., \& Kamiński, S. (2014). Association of polymorphism within LTF gene promoter with lactoferrina concentration in milk of Holstein cows. Pol J Vet Sci., 17(4):633-41.

Zbinden, C., Stephan, R., Johler, S., Borel, N., Bünter, J., Bruckmaier, R. M., \& Wellnitz, O. (2014). The inflammatory response of primary bovine mammary epithelial cells to Staphylococcus aureus strains, is linked to the bacterial phenotype. PLoS One, 9 (1): 1-9.

Zhang, L., Boeren, S., van Hooijdonk, A. C., Vervoort, J. M., \& Hettinga, K. A. (2015). A proteomic perspective on the changes in milk proteins due to high somatic cell count. J Dairy Sci. 98 (8): 5339-51.

Wheeler, T. T., Smolenski, G. A., Harris, D. P., Gupta, S. K., Haigh, B. J., Broadhurst, M. K., Molenaar, A. J., \& Stelwagen, K. (2012). Host-defense-related proteins in cow's milk. Animal Cons, 6 (3): 415-22. 